\title{
Automated software for hydraulic simulation of pipeline operation
}

\author{
Roman Hurgin ${ }^{1 *}$ \\ ${ }^{1}$ Moscow State University of Civil Engineering, Yaroslavskoye shosse, 26, Moscow, Russia, 129337
}

\begin{abstract}
Design of modern water supply systems of large cities as well as their management via renovation of hydraulic models poses timeconsuming tasks to researchers, and coping with this task requires specific approaches. When tackling these tasks, water services companies come across a lot of information about various objects of water infrastructure, the majority of which is located underground. In those cases, modern computer-aided design systems containing various components come to help. These systems help to solve a wide array of problems using existing information regarding pipelines, analysis and optimization of their basic parameters. CAD software is becoming an integral part of water supply systems management in large cities, and its capabilities allow engineering and operating companies to not only collect all the necessary data concerning water supply systems in any given city, but also to conduct research aimed at improving various parameters of these systems, including optimization of their hydraulic properties which directly determine the quality of water. This paper contains the analysis of automated CAD software for hydraulic design and management of city water supply systems in order to provide safe and efficient operation of these water supply systems. Authors select the most suitable software that might be used to provide hydraulic compatibility of old and new sections of water supply ring mains after selective or continuous draw-in renovation and decrease in diameter of distribution networks against the background of water consumption decrease in the cities.
\end{abstract}

Keywords: water supply, design, CAD systems, software

\section{Introduction}

Reliable and efficient performance of modern water supply systems of large cities and management of power flow in extensive and long pipelines requires specific approaches based on the wide use of models [1].

Water services companies that have to tackle those issues often operate large sets of data regarding water infrastructure objects, such as water intake facilities, water treatment plants, pumping plants, pipelines etc. [2]. In these cases, special modern automated CAD systems with various subsystems, which help to solve a wide array of tasks, including systematization, evaluation, analysis and optimization of the most important parameters of any given city's water supply system, are of great help [3]. These automated CAD systems

*Corresponding author: hurgin@mail.ru 
are becoming an integral tool for the management of utility systems, including water supply systems of large cities [4]. The capacities of this software allow operating companies to not only collect all relevant data regarding water supply systems, but also to conduct research aimed at improving certain parameters of these systems, including optimization of hydraulic features of pipelines, a key factor that determines the quality of water $[5,6]$.

\section{CAD systems for design of water facilities}

According to the results of analytical studies, it has been found that, among the CAD systems used to design study and analyze water supply and water discharge systems, the following ones are frequently utilized:

- Autocad Civil 3D, (Autodesk, USA);

- WaterCAD, WaterGEMS, HAMMER, SewerGEMS (Bentley Systems, USA);

- MIKE URBAN automated computer-aided design system (DHI Water \& Environment, Denmark) [7];

- ZuluHydro (Politerm, USA) [8];

- HydroCalc, CityCom-Gidrograf solutions etc.

The approaches to designing, studying and analyzing of the city water supply systems are software specific. It has been found that Russian and foreign water services companies use CAD software designed by Bentley Systems and DHI Water \& Environment more often [9].

\section{Peculiarities of Bentley WaterGEMS application}

Bentley WaterGEMS software can operate alone as well as in combination with ArcGis, Autocad or Microstation, the oldest and most important product developed by Bentley Systems [10].

This software gives its operator an opportunity to not only perform the hydraulic design of a water supply system and tackle water quality issues, but also to conduct cost benefit analysis and calculate energy consumption level.

Bentley WaterGEMS software allows for putting together a design model of a water supply system and for manual input of data of each element. Apart from designing a traditional ring pattern of a pipeline, it is also possible to install shutoff valves, control valves, retention tanks, expansion tanks as well as pumps with various features and operation modes. At the same time, the basic method of calculation might be specified according to one of three classic equations, such as Darcy-Weisbach equation, HazenWilliams equation and Manning equation, depending on reference design conditions and features of analysis of a given water supply system [10].

WaterGEMS software gives its users an opportunity to align water supply systems at various hours of the day, with dynamically modified consumption levels during each hour. It is also possible to allocate various consumers for various nodes of a water supply system; each consumer can choose their own consumption mode. Systems with multiple water feeders (pump stations) may also be analyzed.

When using WaterGEMS software, it is possible to develop different operation scenarios for the water supply system. When utilizing various parameters of pipeline sections, the software determines the best possible option for design or redesign. All in all, Bentley WaterGEMS software is able to collect, analyze, and present large sets of data about water supply networks in large cities. After evaluating and analyzing a particular water supply network, the software provides output data regarding the city water supply system, for example, flow rate in pipelines, water loss, hydraulic and piezometric heads in 
water supply network nodes etc. Moreover, the direction and amount of flow rate in pipelines are determined. WaterGEMS software also provides users with a chance to design piezometric profiles for different directions of a water supply system as well as to plot dependency graphs for different values which change according to hours of the day in water supply network nodes. Besides, another feature has to be noted, which is the ability to plot a 2D diagram of pressure distribution right on various sections of a water supply system; values of pressure distribution at different sections of a water supply system might be represented graphically and then divided. Moreover, critical pressure points of the water network may be singled out.

\section{Application of MIKE URBAN software}

Apart from Bentley WaterGEMS, another CAD software based on the EPANET standard, MIKE URBAN (DHI Water \& Environment, Denmark) [11], is widely used. This software is developed exclusively for calculation of water supply and distribution systems. MIKE URBAN is one of the most well-known and multi-functional software solutions worldwide, and it is used to analyze and study water supply and discharge systems of large cities, alongside products developed by Bentley Systems. MIKE URBAN software solution contains basic economic data, and, by knowing electricity rates, it may be possible to achieve efficient performance of pumps at required system parameters. This software also has a module which calculates hydraulic impact and takes into consideration the start-up and shutdown of pumps, power cuts, cavitation risks etc. Besides, MIKE URBAN software may be integrated with other software solutions, which allows for possible implementation of online operation system or decision-making system (dispatch aid).

High degree of detail of any water supply system element presented in the MIKE URBAN software provides users with an opportunity to input such parameters as the name of pipeline's main pipe, its inventory number, diameter, length, number of node wells, material and year of construction into a database [12].

With the use of models, MIKE URBAN software allows conducting dynamic analysis of water supply system operation modes, determining sections of a water supply system with low flow rates (these sections are subsequently included in flushing plans), organizing efficient control of water quality, especially during the summer period of low water consumption. Moreover, the software calculates the models of load flow when sections of a water supply system are shut down [13].

Therefore, two main tasks that can be solved by designing a hydraulic model of any city water supply system using the MIKE URBAN software may be singled out:

1. Reduction in diameter. The issue of reduction of pipeline diameter, their conservation or liquidation has recently become a major one for Russian water services companies due to the implementation of low water consumption policy in cities. With that in mind, in order to retain and increase sanitary security and efficiency of cities distribution networks, solutions regarding changing the diameters of existing pipelines, liquidation of specific waterways, water mains or duplicate sections of distribution networks are necessary. Taking into consideration the results of pipe diameter and water flow rate and volume and relying on roughness indexes of different materials, it is possible to make these solutions, for instance, decrease pipe diameter, reconstruct specific water mains, replace them with pipes made from different materials possessing different hydraulic features $[14,15]$.

2. Zoning. Division of water supply systems into sections depends on three key factors: difference in drops at sections supplied with water, required free heads and maximum loss of head throughout the network. Pressure at certain sections is managed via simultaneous adjustment of network's pressure relief valves. Pressure in control area may 
be adjusted in real time. This system of pressure control enables the user to solve the following tasks: control pressure at waterworks and distribution networks of any given city, minimize water loss due to pipeline failures and prevent excess head in distribution networks. Thanks to this pressure control system, experts may obtain accurate data about water supply system of the entire city [16-18].

The results of the analysis show that MIKE URBAN software gives an opportunity to handle a wide array of tasks, including the analysis and management of water supply systems in large cities. The functions and options of this software solution are timely and completely coincide with the issues of and requirements for analysis and management of water supply systems of large Russian cities. This CAD solution allows for comprehensive analysis of various options of design and reconstruction as well as making relevant solutions regarding modernization of large water supply networks.

The most relevant software solution intended for analysis and management of a city water supply system should be selected based primarily on the results of the evaluation of requirements and objectives that engineering or operating companies face. Current CAD systems possess a wide range of basic functions and modules used to study various water supply systems. Nowadays, CAD modeling has reached tremendous progress, and the number of software solutions used in water supply systems management has increased drastically, compared to the $1970 \mathrm{~s}, 1980 \mathrm{~s}$ or $1990 \mathrm{~s}$ [19-21].

\section{Conclusions}

1. Automated CAD solutions like Bentley WaterGEMS and MIKE URBAN are considered the best software solutions for water supply systems management in any city. Both products operate on the EPANET industry standard developed exclusively to study and analyze hydraulic models of water supply and distribution systems. Both software products possess a wide range of functions, including design, representation and certification of components of a water supply system. They are also capable of conducting multivariate analysis based on operating scenarios of ring water supply networks, including their draw-in renovation and modernization using current efficient inside protective coatings with a wide variety of pipe wall roughness values, thus securing conditions for compatibility of old and new (or restored) sections of a water supply network.

2. importance of the aforementioned software solutions increases drastically when it comes to tackling the issues of management of water supply and distribution pipeline systems, provision of efficient performance of water supply networks under the conditions of lower water consumption, comparative evaluation of effects of pipeline renovation using various draw-in methods and performance analysis of a pipeline under reconstruction in the absence of hydraulic imbalance when alternative repair materials are used, as well as resources and energy saving when choosing various alternative inside protective coatings of pipelines.

\section{References}

1. N. Abramov, Water supply (1982)

2. M. Somov, M. Zhurba, Water supply. Vol. 1. Systems of water withdrawal, supply and distribution (2008)

3. Y. Galperin, WSAST, 6, 13-16 (1999)

5. S. Khramenkov, Strategies of modernization of water supply systems (2005)

6. V. Orlov, Pipelines. Automated maintenance of projects (2015) 
7. N. Makisha, E3S Web of Conferences, 6, 01002 (2016)

8. ZuluHydr, hydraulic calculations for water supply systems. Politerm company. URL: www.politerm.com.

9. S. Govindan, CAD and graphics, 4, 36-38 (2009)

10. D. Borisov, CAD and graphics. 5, 64-68 (2009)

11. MIKE products by DHI Water \& Environment. URL: www.mikebydhi.com. Accessed date: December 5, 2012

13. B. Rajani, Urban Water, 3,151-164 (2001)

14. M. Fattakhov, Design and use of plastic pipelines in oil industry (2009)

15. M. Najafi, Trenchless technology of piping: installation and inspection (2010)

16. S. Abulgafaov, Combined technology of draw-in repair of pipelines of irrigation systems (2004)

17. O. Davydenko, Increase of efficiency and reliability of draw-in repair of pipelines using toral engines (2013)

18. A. Zwierzchowska, Technologie bezwykopowej budowy sieci gazowych, wodociagowych i kanalizacyjnych (2006)

19. A. Kulakov, N. Makisha, MATEC Web of Conferences, 112, 10019 (2017)

20. GOST 52134-2003 Thermoplastic pressure pipes and their connecting elements for water supply and heating systems (2003)

21. N. Makisha, A. Kulakov, MATEC Web of Conferences, 112, 10018 (2017) 